This paper outlines some potential strategies for growing revolutionary left organisations in Aotearoa, using the case study of People Against Prisons Aotearoa (PAPA), previously known as No Pride in Prisons. Lamusse provides a brief history of PAPA and outlines their experiences organising with the prison abolitionist organisation since its founding, sharing the lessons they learned about growing revolutionary left organisations in Aotearoa. They argue that to ensure democracy, transparency, and a fair division of labour, left organisations need clearly defined decisionmaking structures and roles. They demonstrate how, since PAPA transformed from a structureless organisation, it has not only become more democratic, but has also become a far more effective movement. 


\section{Strategies for Building the Revolutionary Left}

TI LAMUSSE

People Against Prisons Aotearoa’s (PAPA) first explosion onto the public stage perhaps remains one of its most memorable actions. Carrying a banner that said 'No Pride in Prisons', three activists climbed over the barriers at the 2015 Auckland LGBTIQ Pride Parade and attempted to stop the police float from progressing down Ponsonby Road. The protest, as well as the parade security's violent response to it, captured the imagination of large numbers of mostly young LGBTIQ people. From that moment a movement called No Pride in Prisons (NPIP) emerged. This paper outlines a brief history of NPIP (subsequently renamed PAPA), our experimentation with different organising methods, and changes in our scope, name, and capacity for action. None of the various organising strategies and methods I outline here are new. However, I hope that the specific case study of PAPA demonstrates some concrete ways in which the revolutionary left can improve our organising. While the lessons PAPA has learned are not applicable to all struggles on the revolutionary left, this paper outlines some of the ways to avoid the mistakes PAPA made and build greater capacity for collective action. 


\section{A brief history of NPIP/PAPA}

PAPA's inception can be traced back further than the 2015 Pride Parade protest. Many of the early organisers met each other through involvement in the 2013-2014 student protests against university fees and financialisation at the University of Auckland (UoA). At this stage, the student movement was heavily influenced by the organising principles behind Occupy Auckland, particularly the principles of structurelessness, horizontalism, and leaderlessness. For many of us who were new to organising at the time, this was, in theory, an exciting new way to make decisions, where it appeared that no one person had any more power than anyone else. It seemed like a way of organising where everyone's voice mattered equally, and anyone could get involved.

In mid-2014, myself and a small number of other LGBTIQ from the student movement became particularly interested in queer politics. The New Zealand Parliament had just allowed same-sex couples to take part in the bourgeois institution of marriage. We were concerned that this move, as well as the co-option of the queer struggle by big business, was causing a de-radicalisation of the queer movement. We hoped to spark a rebirth of a radical queer liberationist movement. Because our collective experience of organising was, at that stage, entirely limited to our experience in the UoA student movement, we simply replicated the organising methods we had seen our comrades use.

In particular, we had seen our comrades use reading groups as a starting point for organising movements. As a way to hopefully start a new queer liberationist movement, we did this too, forming our own reading group focused on queer theory and politics. ${ }^{1}$ In our fifth session, we read Angela Davis' Are Prisons Obsolete, Bassichis, Lee and Spade's 'Building an Abolitionist Trans and Queer Movement with Everything We've Got', and

1 Three other comrades and I gushingly reflected on this period of the student movement in Ti Lamusse et al., 'Reading and Rioting: Student Politics Beyond the University,' New Zealand Sociology 30, no. 2 (2015): 73-86. Although the authors now disagree with much of its content, the article outlines the kind of politics and thinking we were engaged in at the time. 
Bayour's 'Occupied Territories, Resisting Women'. ${ }^{2}$ This session laid the groundwork for our thinking around a queer politics of prison abolition that eventually led to NPIP. Most of the people who attended that session would later become founding members of NPIP.

The belief in prison abolition, when taken seriously, does not lend itself to idleness. There is so much urgency to the material suffering caused by imprisonment that material actions are required to address it. That meant we felt compelled to do something when it was announced that the New Zealand Police and Department of Corrections staff would in 2015, for the first time, march in uniform in the Auckland Pride Parade. We saw pride parades as commemorations of the gay liberationist riots that demanded a world without heterosexual domination and police violence. The inclusion of police and corrections officers in the parade sent the message that the violence of the criminal justice system was acceptable. We decided we had to intervene.

Consequently, on the evening of the parade, three of us stormed onto Ponsonby Road with a banner and yelled at police officers as they approached us. We were quickly escorted off the road by parade officials and police officers. In the process, a security guard picked up one of the protesters and threw her onto the ground, breaking her arm. ${ }^{3}$ In the emergency room, waiting for news about our comrade, we were writing press releases about what had happened. In that moment of intense pressure and anxiety, NPIP was formed. We consisted of the three protesters and handful of supporters at the parade, as well as some other comrades from the queer theory reading group.

Following its formation, NPIP did very little. We held no regular meetings; we communicated informally through friendship groups; and

2 Angela Davis, Are Prisons Obsolete? (New York: Seven Stories, 2003); Morgan Bassichis, Alexander Lee, and Dean Spade, 'Building an Abolitionist Trans and Queer Movement with Everything We've Got,' in Captive Genders: Trans Embodiment and the Prison Industrial Complex, eds. Eric Stanley and Nat Smith (Edinburgh: AK Press, 2011), 15-40; Elham Bayour, 'Occupied Territories, Resisting Women: Palestinian Women Political Prisoners,' in Global Lockdown: Race, Gender, and the PrisonIndustrial Complex, ed. Julia Sudbury (New York: Routledge, 2005), 201-214.

3 Ti Lamusse, 'Politics at Pride?' New Zealand Sociology 31, no. 6 (2016): 49-70. 
we had no defined kaupapa (grounding principles) or structure, although undefined and unspoken kaupapa and structure emerged over time. For about four months NPIP simply remained the name of the group that protested the Pride Parade. That changed when one of our core organisers noticed in the news that a transgender woman had been sent to a men's prison. We wrote to her to see if there was any way we could support her. As it turned out, she had applied to be transferred to a women's prison months previously, but Corrections had delayed her application. We then organised a hunger strike in late-August, demanding that she be transferred. Just hours into the strike, she was sent to a women's prison.

We knew we had some momentum behind us following this successful action. We did what we had learned to do from the student movement in this case: after a big action, hold a public assembly to grow the membership. While we certainly had some interest from the public about this issue, there was not really an organisation that people could easily identify, join, and organise with. We were not able to truly capture that momentum. We had another couple of months of very little action, with a couple of exceptions, until the summer of 2015/2016 when our student-members were on break from study. In that time there was a flurry of activities leading up to the 2016 Pride Parade. We had decided a couple of months earlier that we wanted to protest the parade again but that we wanted it to be bigger. ${ }^{4}$

The lead-up to the 2016 Pride Parade was the beginning of the end for the way NPIP was organising. A core of about three of us were doing between 10 and 40 hours per week of work preparing for the parade. We were regularly writing and producing propaganda, working through tactics, preparing media, and ensuring that everything was ready for our blockade. Just days before the parade, the three of us were at breaking point. We were worn down by the sheer amount of work, the high stress, and the extraordinary level of decision-making power and responsibility we had. That day, us three sat down to figure out what would happen to NPIP if we were all sectioned under the Mental Health Act and forced into compulsory state

4 For PAPA's account of the 2016 Pride Parade see Sophie Morgan and Ti Lamusse, 'There Was Only One Auckland Pride 2016 and It Started on Karangahape Road,' People Against Prisons Aotearoa, February 22, 2016, http://blog.papa.org.nz/ post/139768619390/there-was-only-one-auckland-pride-2016-and-it. 
care-something that felt like a possibility at that time. We wrote down every job that each of us did that no one else was doing and tried to figure out a way to redistribute labour and decision-making. It was the rudimentary beginning to what would become a complete overhaul of how we organised.

\section{Structurelessness and how it restricts revolutionary potential}

How, then, did NPIP become an organisation that relied on the immense amount of labour of such a small number of people? It is arguable that the core group of organisers, to some extent, did this to ourselves. The decision to put in more work could have come from a desire to have a greater say about what the organisation did, or how it presented itself and its ideas. These core organisers could also have simply had more time or capacity to contribute or were more invested in the kaupapa. More cynically, it could have been an attempt to take control of the organisation for the purposes of self-promotion or careerism.

Even if all of this is true, the problem here is not the bad decisions of malevolent comrades, but the structures in place (or lack thereof) that allowed this to happen. Even when a group of people decide they want no formal structures in their group, informal structures will nonetheless emerge. All our possible decisions are both enabled and restricted by the social world in which we live. Human beings are social animals. ${ }^{5}$ Human life is defined by our relation to other people. Without others we would not have the language we need to communicate or the food we need to sustain ourselves. Social relations structure our lives because we are always reliant on others for both our survival and our sense of who we are. ${ }^{6}$ These structures can be both obvious and clearly defined, or unspoken and difficult to identify. Structures can similarly be both oppressive and emancipatory-they can both undermine and encourage democracy,

5 Karl Marx, Capital: A Critique of the Political Economy, Volume 1, trans. Ben Fowkes (London: Penguin Classics, 1976 [1867]).

6 I develop this line of thought in greater detail in my MA thesis: Ti Lamusse, Grieving Prison Death (M.A., University of Auckland, 2017). 
equality, justice, and freedom. However, it is impossible, as social beings, to do away with structures entirely.

It is precisely this attempt to organise without structure that undermines organising itself and leads to the kind of burnout that NPIP organisers experienced in the lead-up to the 2016 Pride Parade. At that time, NPIP had adopted the organising principle of structurelessness, where there were no formal, explicit, and easily recognisable structures. This structurelessness emerged organically through the process of organising itself. In practice, there was a general, unspoken agreement that decisions should be made democratically or by consensus and that everyone played an equal role of equal importance in the organisation. Decisions could be made by anyone who came to a meeting or was part of an organising chat, and membership was theoretically open to anyone. No one held any roles, and no one was responsible for doing any tasks unless they volunteered to do it on an ad hoc basis.

There are certainly some benefits to organising in this way. NPIP's first, relatively successful, actions were organised in this way. For very small groups, having too much formal structure can be cumbersome and overly bureaucratic. A lack of formal structure can certainly work for groups which want to remain small in order to build trust, ensure secrecy, or only mobilise small numbers of people. For these groups, structurelessness may not be an issue, as there would not be enough people for unofficial leaders to emerge, and it should be relatively transparent who is doing what work and why.

While structurelessness may have worked at the inception of NPIP, after a year of minimal activity and yet exhaustion from the core organisers, we were not really a functional organisation. Rather, structurelessness was hurting our capacity to organise in four key ways. First, our kaupapa was not clear. Regardless of whether kaupapa is written down or stated explicitly, a group of people working together for change have some degree of shared principles underlying their work. By February 2016, we had never discussed what we believed or what our goals were. While our founding members were all committed to prison abolition, there was also a tendency among some new members, and many of our online supporters, to see us as primarily trans-rights protesters. For some of us, the uncertainty around 
the kaupapa caused an uncertainty about how much effort one should put into the movement. It also caused conflict around messaging, or how we talked about issues publicly when they came up. Put simply, without a common and collectively agreed-upon kaupapa we did not know who we were or what we wanted. Without a clear vision, it was difficult to talk to media or even friends and family about NPIP. NPIP meant numerous things to numerous people, without any of those meanings being decided collectively or democratically.

Second, this uncertainty extended to our membership more broadly. Not only did those of us who considered ourselves members have very different ideas about what our principles and purpose were, it was not entirely clear who got to call themselves members. On the one hand, we had some people who were actively involved in the Auckland branch and who helped to set up our pen pal network but did not consider themselves members. On the other hand, we met young people at hui or online who called themselves NPIP members but who none of us had ever met or heard of before. Each of these situations provoke different concerns.

In the first instance, someone who was crucial to the functioning of NPIP did not consider herself a member, which indicates that she did not feel that she was legitimately recognised as belonging in the organisation. In feeling that she was not a member, she felt like she did not have the right to contribute to decision-making, or that she was an equal participant. The second instance could be viewed favourably, in that NPIP was able to reach young people and make them feel like they belonged to our organisation. However, by claiming to be members of NPIP, those people were also claiming to represent us and our kaupapa. If those people represented NPIP in a reactionary or oppressive way, our structureless and open membership provided us with no ability to hold them to account or even to know that they were claiming to be members.

Membership is crucial for any revolutionary organisation. It is our members who get the work done, who carry our message, and who fully agree with our kaupapa. Although it is tempting to believe that open and undefined membership makes it easier for people to be involved and to identify with an organisation, that is not necessarily true and, if it is true, it 
is not necessarily a good thing. The lack of clear membership criteria can, in fact, be very alienating. People do not know in advance what they are signing up to. Where it is not clear what membership entails, but a person wants to get involved, they need to go to multiple meetings to figure out what it means to be a member. For those of us with very limited time, uncertainty about what membership means can be a barrier to participation. On the other hand, having clear criteria can enable people to legitimately identify as a member of an organisation, which can both foster greater bonds of solidarity and better enable the recruitment of new members.

Uncertainty around who exactly was a member of NPIP caused a third issue: a lack of democratic decision-making processes. Aspirations for democracy and equality undergird the structureless mode of organising. In practice, though, structurelessness undermines both principles. The first stage of establishing a democratic decision-making process is establishing who gets to take part in the decision. In an ideal world everyone would be able to take part in important decision-making that concerns their lives. Right now, however, we live in a capitalist system on colonised land, which is saturated with racism, sexism, homophobia, transphobia, and various other forms of oppression. In deciding something like whether to protest the Pride Parade, either no decision or a reactionary decision would result from everyone, including homophobes, police officers, neo-Nazis, and corporate CEOs, participating in that protest. Revolutionary left organisations should not want police officers and corporate CEOs involved in our decision-making, because we want to create a world in which those jobs do not exist.

Consequently, all revolutionary left organisations must (and do) exclude some people from being able to participate in decision-making. This can be for various reasons, both good and bad, such as geography, political position, child-carer status, age, and ability. Recognising that some exclusion is embedded in the nature of social movements, explicitly outlining what those reasons are, and explicitly addressing unintended exclusions is required to build an inclusive and emancipatory movement.

As noted, in our early days, NPIP had no clear criteria for what membership meant. That meant that it was not always clear who got to 
make decisions and when. Usually, decisions were made at meetings or in an organising chat; however, they were sometimes made when a bunch of friends from NPIP got together and talked about the organisation. Without any defined decision-making processes, these decisions were all equally legitimate. At meetings, decisions were made by the people attending and could be made about any topic, including anything about our core beliefs. Although it never happened with NPIP, this kind of unofficial decision-making process lends itself to undemocratic and abrupt reversals of positions and principles. There were no mechanisms in place to ensure, for example, that a single meeting of four people could not choose to come out in support of building a new prison, something which would be in contravention of our unclear and unstated kaupapa. Without outlining how and by whom democratic decisions are made, we fundamentally undermined our organisational democracy and left ourselves vulnerable to co-option.

In practice, the lack of democracy was more benign and mundane, but no less important. As is probably the case in many structureless organisations, most decisions are made by the people who do the work. While a broader group may decide to organise a protest about something at a meeting, many decisions about how that protest is organised occur outside of meetings. Decisions as small as choosing which font to use on a poster, or as big as what to include in a press release, are ultimately decided by the people who are willing and able to do the work. This division of labour and decision-making enables the work to get done. The problem arises when, out of habit or assumption, certain people are simply expected to do certain work, without clear and democratic empowerment to do so.

This implicit expectation that a certain person will do certain work undermines organisational democracy in several ways. It provides that person with not only the responsibility to do the work, but also the unofficial power to decide what that work looks like. This can grow the power that person has within the organisation more generally, making them indispensable for certain tasks. This, along with a lack of a clear decision-making processes, makes it hard to overturn decisions made by these people, or to hold them to account when they do something wrong.

The result of this is a concerning trend of authoritarianism within 
structurelessness, a trend I have witnessed not only in NPIP but in other organisations that adopt the structureless model. In the early days of NPIP myself and two other core organisers, who were doing most of the work, would come to meetings with our own plans and ideas. Almost always, those ideas were adopted by the organisation with little or no disagreement. While it may be that we just had fantastic ideas that were unquestionably the best course of action, that seems incredibly unlikely in hindsight. A more accurate assessment of the situation was that the people at these meetings either accepted and respected our experience or were unwilling to disagree with us because we played such an important role within the organisation. In this way, these unspoken power-relations and division of decision-making undermined the democracy of the organisation and produced inequalities in membership.

Fourth, the uneven distribution of labour is the flip-side of the problem of the uneven distribution of power. The core group of three of us were simply doing far too much work. We did everything from administrative tasks (answering emails and organising meetings), to propagandising (writing press releases and producing content for social media), advocacy (visiting prisons and starting a pen pal network), and organising our other political work. It was entirely unsustainable and gave us far too much power within the organisation. This led to the burnout we experienced in the leadup to the 2016 Pride Parade. At that stage something needed to change, not only for our personal health but for the health and growth of NPIP.

\section{Building emancipatory structures}

Following Pride 2016, NPIP started a long process of change in the way we organised. We started by putting in place some structures that could help to facilitate our organising. We started meeting regularly and implicitly established meeting etiquette around announcement of meetings, facilitation, and minuting. The importance of regular, well-structured meetings cannot be stressed enough. Although they can feel tedious and, at times, pointless, they are essential for keeping up momentum, making important decisions, and ensuring that work gets done. 
At one of these early meetings in Auckland following the 2016 Pride Parade, we decided that we needed to outline what we want to change in the criminal justice system. Using our informal decision-making processes, we came up with a list of about 50 demands. We then divvied up the writing of those demands, with the intention of publishing them online. When we realised the scale of these demands, we decided to instead publish them as a book, launching it at the 2016 Social Movements, Resistance, and Social Change conference in Wellington.

The process of writing brought up multiple questions for how we organised, including how we made democratic decisions and the role of the different branches of the group. Most importantly, however, the ambition of the project that we laid out for ourselves in the Abolitionist Demands required a seriousness of organising that we simply did not have at that time. By laying out our desire for what we wanted to change, we had to get far more serious about how to enact that change. Many of us realised, through this process, that we needed to be much larger and mass-based if we ever wanted to transform society.

Throughout the time of writing the demands from April to September 2016, several of us were also becoming increasingly involved with other leftist organisations in Auckland. Some of the core members of NPIP started organising with Auckland Action Against Poverty and Auckland Peace Action, and some joined the early discussions that would eventually lead to Organise Aotearoa. This expanded our experience of how we could organise and, for many of us, helped us to re-envision what NPIP could look like. PAPA today owes a considerable debt to the experience of comrades in other organisations who taught us through their own example what effective organising can look like.

Shortly after the launch of the Abolitionist Demands in September 2016, we decided to hold hui so that we could establish a clear structure and kaupapa. The first decision we made was that we could no longer continue as a solely queer and transgender prison abolitionist organisation. The task of prison abolition is far too large for just LGBTIQ people to be responsible for enacting it. The harms of imprisonment also extend well beyond our communities. To seriously fight for prison abolition, we decided to become 
a mass-based organisation, rather than an identity-based organisation.

On the weekend of that first hui, we talked from 8am to midnight on both Saturday and Sunday to establish an organisational constitution. Three of us had gone away and written a draft, which was then dissected and changed, line-by-line, until we enacted it by unanimous consent.

The constitution empowered NPIP to do so much more than we had before and in a more democratic, mass-member-driven manner. There are numerous ways in which it did this. First, it identified the key areas where we needed to do work. For example, we wanted to do research, media, prisoner advocacy, parliamentary advocacy, political outreach, social media, organise transformative justice, and continue to run our pen pal network. Before our restructuring, we were doing many but not all of these things. Where we were doing these tasks the problem was that they were being done by a very small number of burnt-out people. The constitution tried to address this. It formally established working groups of members who were keen to work on each of those areas. It also established co-ordinator roles for each of the working groups. These co-ordinators are elected positionholders, who are responsible for ensuring that the working group does what it is constitutionally empowered to do. We also established other elected administrative roles for fulfilling administrative tasks that are important, but often forgotten.

In other words, we figured out all the work we wanted to do as an organisation and then created democratically elected roles to ensure that it happened. By formalising exactly what we wanted to do and officially empowering people to do it, we made the decision-making clearer and democratically accountable. Although the working group co-ordinators are ultimately responsible for getting things done, most decisions are made collectively and collaboratively within working groups. Instead of one person making decisions without a democratic mandate, co-ordinators are elected from the membership and can be recalled, and their decisions overturned.

The development of new organising technologies such as instant messaging has also meant we are able to organise more efficiently and effectively at a national level than our predecessors were capable of. The constitution truly transformed us into a national organisation. Before the 
restructuring of NPIP we had branches in Auckland, Wellington, and Dunedin that did not work well collaboratively. In fact, almost all the work and decision-making were made in Auckland with little-to-no input from Wellington and Dunedin comrades. For example, the Abolitionist Demands were formulated in the Auckland Branch, all media came from Auckland, as well as advocacy and our pen pal network. The creation of national working groups fundamentally changed this. By formalising these structures, members from anywhere in the country can join a working group in areas they want to contribute to, regardless of whether there is a branch in their area. It also meant we could nationalise core tasks and avoid duplicating labour and costs, as well as grow solid bonds of solidarity between members and branches.

We also became a truly national organisation by forming our National Organising Committee (NOC). This body is made up of all the working group coordinators, administrators, and representatives from each of the branches. Each of these position-holders comes together to report on what we are doing, seek advice from one another, and strategise at a national level. Having the NOC meet regularly means we are regularly reflecting on the work we are currently doing and could be doing in the future. The NOC itself, however, is limited in its power. Any ideas it comes up with need to be discussed and voted on by the national membership. That is because the membership holds the greatest decision-making power of the organisation, including the power to overturn and redirect the decisions of the NOC.

Following the lengthy hui in which we established our constitution, we held another hui where we collectively wrote our kaupapa with which one had to agree in order to join NPIP. As we had already written our Abolitionist Demands by then, this process was simply a distillation and clarification of our minimum principles. From this point, we had also realised that we may need to change the name of the organisation at some stage. We had heard from several prisoners and their whānau that the name No Pride in Prisons made them think we were saying it was shameful to be in prison. The name was becoming a barrier to reaching out to people who we wanted to join the organisation.

We then started a long process of deciding whether to change our 
name. First, we brainstormed name ideas in branches. Then, the NOC took the dozens of suggestions and created a shortlist of name ideas, which the membership then voted on, choosing 'People Against Prisons Aotearoa'. At our first Annual General Meeting we chose between keeping our name as No Pride in Prisons and changing it to People Against Prisons Aotearoa. Our membership unanimously voted in favour of changing the name. While we have made some changes to the way we organise since then, including creating new roles, campaigns, and working groups, changing our name represents the final major transformation of our organising.

\section{What structure enables}

Establishing a constitution that clearly outlines decision-making, membership, and principles addresses each of the issues I outlined in the second section of this paper. First, having clarified for ourselves what our kaupapa is, it is much easier to explain to others what we believe. While we do not and cannot agree on everything, sharing some basic principles allows us to work together toward our common goals. As a result, PAPA has changed from what was an entirely identity-based group to a broadleft prison abolitionist organisation, which includes comrades from various tendencies across the radical left. By clarifying our points of unity, we can and do take action to achieve our collective goals.

The constitution also clearly outlines how decisions can be made and by whom. It puts in place clear processes for overturning decisions that the membership either disagrees with or that the decision-maker was not empowered to make. Having working groups do most of the work, and having them clearly defined and easy to join, takes power away from coordinators and ensures collaboration and collective decision-making. As very little work is done by simply one person, it is difficult for any individual to become indispensable and hold additional power over the membership as a result.

Having clear definitions of membership also gives potential new members a concrete idea of what it means to be a member and how they 
can get involved. This can partially explain why, in the first year since our restructuring, our membership more than quadrupled. However, even that figure understates the effect of restructuring on our membership. Whereas prior to the restructuring just a handful of people were actively organising with PAPA regularly, that number immeasurably and exponentially increased. Not only do we have far more members, we also have far more members who are willing and able to do work.

This is also partially explained by the numerous new ways in which our members can participate, a result of the restructuring. Not only can we join working groups or run for positions, our branch meetings also have a greater purpose. As prior to the restructuring most of the important decisions were being made unofficially from the Auckland Branch, our branches in Wellington and Dunedin struggled to get off the ground and to find a purpose. The restructuring enables the national membership to weigh in on important decisions and formally empowers branches to take more action at a local level. Our branch meetings are now a mixture of planning local events and running collective internal education sessions where we learn about the criminal justice system and how we can change it. Accordingly, our branch meetings are both more interesting and productive.

A cynic may argue that all this restructuring amounts to is additional bureaucracy. Even if this were true, bureaucratic inconvenience is a price worth paying to ensure that decisions are made democratically. In practice, however, PAPA makes decisions incredibly quickly and can respond to issues as they arise. Because we have groups empowered to make decisions about certain things, it is usually clear who gets to make decisions and how. Also, having a national body means that representatives of all sections of the organisation can collectively deliberate and decide matters in cases of urgency.

Other than becoming more democratic, the restructuring resulted in an explosion of activity from PAPA. From February 2015 until November 2016, when we established our constitution, NPIP held a handful of protests and direct actions, started advocating for one or two prisoners in Auckland, started a pen pal network with a dozen or so prisoners, and had a semi-active presence on social media. However, since November 2016, this work was split up between many more comrades, meaning we have 
been able to achieve far more. Our advocacy network is visiting dozens of prisoners across the country; our pen pal network connects more than 300 prisoners with more than 500 people on the outside; we regularly produce high-quality research for both internal and external use; we regularly lobby the government on legislative changes to the criminal justice system; we have a greater presence in the media; we hold community workshops about transformative justice and provide transformative justice interventions; we run nationally coordinated campaigns; and we continue to organise in solidarity with our comrades across the radical left. We also continue to expand what we do, when our capacity allows for it. There is simply no way we could have had the capacity to do all this without restructuring the organisation.

By all measures, we do as much as one would expect from an NGO with numerous paid staff members. Instead, all our members and position-holders volunteer our time because we believe in the kaupapa of prison abolition and have structures in place to make the most out of our work. If nothing else, our restructuring has enabled us to do substantially more as an organisation and in a way that is less likely to cause burnout in our members.

\section{Remaining Problems}

Of course, this is not to say that PAPA is a perfect organisation, without any remaining issues. We still have many lessons to learn and a lot left to do. There are three key issues that continue to undermine our organising. None of these are unique to PAPA or new to the radical left.

First, as an organisation with a kaupapa that is fundamentally opposed to the interests of the ruling class, it is not in the wealthy's interest to materially support us. We rely on small-scale weekly donations from our members and supporters, fundraising events, and merchandise sales. Because we never want to be held hostage by the interests of funders, we do not seek out funding from big donors. Our lack of money, however, restricts the kind of work we can do. In the not-too-distant future, and if our current rate of organisational growth continues with the same levels of funding, we will not be able to fully fund our pen pal and advocacy networks, our new prisoner newsletter, and our free-of-charge transformative justice 
workshops. Our continued existence depends on our community's belief in the importance of the work we do and its financial commitment to it.

Because of our low levels of funding, we must do almost everything ourselves, on a volunteer basis. That raises the second major issue for our organising going forward: ensuring that our members have the time and capacity to contribute to our work. PAPA's restructuring was only successful because there were people willing to put in work but who, under our previous structurelessness, did not know how they could get involved. The structure itself does not ensure that organisational work will occur, but it does enable people who want to get involved to do so more easily. This means that PAPA's long-term viability is also entirely dependent on our members remaining committed to our kaupapa. Our aspirations for the new community programmes and political interventions are limited by the amount of time and capacity people can put into them. That is why a mass-based membership is so important, and why we are always seeking to grow our membership.

Finally, PAPA's potential for revolutionary change is restricted by the fact that PAPA alone cannot enact the changes we want to see in the world. From PAPA's analysis, the criminal justice system is an entrenched part of the capitalist mode of production. To not only abolish prisons but to make them redundant, we need to move beyond capitalism. Prison abolition requires a world without exploitation and inequality, and where everyone's needs are met. As we argue in our Abolitionist Demands, 'the prison will not be abolished without a revolution in social and economic conditions.?

The scope of the change required is so great that it cannot be fought solely on the front of prison abolition. The radical left in Aotearoa needs to work together better to enact our shared vision. That does not only mean turning up to each other's protests and events, which is something we do well. It requires building an organisation that can make demands for all of us and build our collective power. The economic, environmental, and social crises we face remain far too serious to fight for small wins from separate and distinct movements. The breadth of our struggle requires a

7 Ti Lamusse, Sophie Morgan, and Emilie Rākete, eds., Abolitionist Demands: Toward the End of Prisons in Aotearoa (Auckland: No Pride in Prisons Press, 2016), 9. 
broad organisation that can link us all together. While our movements are crucial to making the case for the world we want to live in, we also need a party of the revolutionary left for ordinary people to come together to collectively transform society. We need to get organised. We need to get mobilised. We need to be ready and willing to change the world, because our future depends on it. 